\title{
Numerical Simulation Analysis of Karst Tunnel Water Bursting Movement
}

\author{
He Baohua ${ }^{1, a^{*}}$ \\ ${ }^{1}$ Shenhua Zhunchi Railway Co. Ltd, Shuozhou, 036002, China \\ $\mathrm{a}^{*}$ hebbaohua@sohu.com
}

\begin{abstract}
Keywords: Karst; tunnel; water inrush; movement pattern
Abstract. The karst water is one of the main geological disasters in tunnel construction in Karst area. The disaster of water inrush in karst tunnel is studied in this paper. FLOW-3D is used to simulation movement patterns of water inrush in karst tunnel based on BaoFeng tunnel engineering. The following contents are studied. Firstly, the total duration in tunnel and the characteristics of tunnel water inrush were studied. Secondly, 140s time before the water inrush from the left tunnel discharge, the main reason for the lowest surface for the cross channel is slightly higher than that in the bottom of tunnel. But 140s after the water inrush from the left tunnel discharge, the drainage discharge by the right line, the main reason for the decrease in left line tunnel velocity, kinetic energy due to the force of gravity, resulted in the initial stage of the water began to flow of the tunnel face and the formation of turbulence. Thirdly, at the beginning stage, water gushing speed was up to $17 \mathrm{~m} / \mathrm{s}$, and the waves move forward. Fourthly, the viscosity and density of water inrush has little influence on the rate of water inrush. The research will provide the basis for karst tunnel water inrush prevention theory.
\end{abstract}

\section{Introduction}

Karst is the General term for the phenomenon generated by these functions including water soluble rocks (carbonates, gypsum, rock salt and so on) to chemical corrosion, water erosion, erosion and avalanches and other mechanical action supplemented by geological processes. According to the incomplete statistics [1-2], the karst area is close to $50 \times 106 \mathrm{~km} 2$ all over the world. They are mainly located in the United States, France, Britain, China and South Africa, the Balkans and other countries or regions. The karst area located in China is more than $3.443 \times 106 \mathrm{~km} 2$. There are karst area throughout the provinces, autonomous regions and municipalities. Southwest in China is the abundant karst cave region. Recently bursting hazard of karst tunnel water has become the most common and most vulnerable of underground construction in karst area as well as one of the most damaging disasters [2-4]. Although many research results on occurred mechanism the karst tunnel bursting water disaster, bursting water disaster of karst tunnel didn't get curb due to rock dissolved of development and containing water and guide water constructed assigned save law of complexity and concealment. The most fundamental cause is not to settle the migration form of rock dissolved tunnel bursting water. It is found out by studies that movement form of rock dissolved tunnel bursting water became a key to prevent bursting water disaster. Migration driving force of groundwater in karst tunnel come from gravity and external water pressure [5]. According to karst water bursting in tunnel mode of hydraulic connection between water contacts with the outside world, driving force of tunnel in karst water inrush is divided into gravity-gradient flow and pressure gradient flow [6]. The driving force of water movement patterns of karst Tunnel will be divided into gravity-driven and pressure-driven according to the similarities and differences water of movement patterns of groundwater migration of karst tunnel [4-6]. By baofeng tunnel of morphological and genetic analysis of water inrush, BaoFeng tunnel groundwater migration driving force of water inrush is mainly affected by the sudden gravity gradient caused by its own gravity flow water body due to external water pressure rather than gravity-gradient streams are usually small or zero, and its impact on the water movement patterns can be ignored. Baofeng tunnel water primarily developed large scale filling, or half-filled caves or Caverns, relative to its own volume, and water volume, hydraulic connection with the outside world was weak. Such characteristics of water inrush are respectively water is large 
in scale, expose the larger, and initial inrush of water inrush of water. But the water pressure is low, and outstanding short, sudden water contains a mixture of mud, sand, stone, its density and viscosity than water, liquidity slightly worse. Such water inrush is mainly dominated by storage of water inrush in a short time. Hydraulic connection with the outside world negligible can be water, water paths and tunnels as a stand-alone system for analysis to analyses the flow of water bursting and its destructive power. The potential water bursting geological of Baofeng tunnel is the vicinity of karst groundwater in karst cavity fillings. Water pressure is low during the process of inrush water primarily under its own gravity and gravity driven flow. This does not meet the characteristics of water bursting pressure-driven. Study on Karst water gushing in tunnel gradient of gravity-driven flow of movement patterns has not been seen. The study will provide the basis for Karst water bursting in tunnel disaster prevention theory.

\section{Geology and Hydrology}

Baofeng tunnel began from DK10+338 and end from DK17+715. The whole length tunnel is $7377 \mathrm{~m}$. The inclined shaft of tunnel consists of the following four lengths. The first full length inclined shaft is $425 \mathrm{~m}$. The intersection and main tunnel mileage is $\mathrm{D} 2 \mathrm{~K} 11+600$. The second full length inclined shaft is $600 \mathrm{~m}$. The intersection and main tunnel mileage is D2K12+900. The full length inclined shaft of third $1041 \mathrm{~m}$. The intersection and main tunnel mileage is D2K14+750. The fourth full length inclined shaft is $482 \mathrm{~m}$. The intersection and main tunnel mileage is D2K16+350. For the first inclined shaft, the measured area is characterized by tectonic erosion, erosion in low mountain areas, terrain waviness, and transverse gully development. Precambrian bedrock of Kunyang group Black Mountain group (Pt1hs), slate clips sandstone, rock dominated by thin layered, under the influence of inlet water camp strike slip fault, joints, rock breaking, poor surrounding rock stability, groundwater dominated by bedrock fissure water and moisture content is moderate. First deviated from the dachunhe reservoir is close and may be affected. First bear hole part with the biggest inflow of inclined shaft for $6268 \mathrm{~m}^{3} / \mathrm{d}$. For the second shaft, the measured area is characterized by tectonic erosion, erosion in low mountain areas, terrain waviness, and transverse gully development. Precambrian bedrock of Kunyang group Black Mountain group (Pt1hs), slate clips sandstone, rock dominated by thin layered, under the influence of inlet water camp strike slip fault, joints, rock breaking, poor surrounding rock stability, groundwater dominated by bedrock fissure water and moisture content is moderate. The second bear hole part with the biggest inflow of inclined shaft for $5510 \mathrm{~m}^{3} / \mathrm{d}$. For the third of inclined shaft, a bedrock for the sinian of Kunyang group Black Mountain group (Pt1hs), slate clips sandstone, slate dominated by argillaceous slate, soft quality. The joint development, rock crushing and strong weathering zone in big thickness seriously are affected by the structure. Water medium is dominated by fissure water in groundwater. Third of inclined shaft cover holes maximum water inflow is expected to $5000 \mathrm{~m}^{3} / \mathrm{d}$. For the fourth of inclined shaft, the measured area is characterized by tectonic erosion, erosion in low mountain areas, terrain waviness, and transverse gully development. Precambrian bedrock of Kunyang group Black Mountain group (Ptlhs), slate clips sandstone, rock dominated by thin layered, joints, rock crushing, thick, strong weathering zone, dominated by bedrock fissure water groundwater, water medium. Fourth cover hole is expected to the largest inflow of inclined shaft for $4998 \mathrm{~m}^{3} / \mathrm{d}$.

\section{Numerical simulation analysis}

\section{Computational model}

According to the definition of a gravity driven water gushing in tunnel and its characteristics, water burst of baofeng tunnel takes respectively into account cross-channel, excavation about line height and bad situations such as water movement simulation of construction. Gravity gradient-driven simulation considers effects of water inrush of water bursting in tunnel characteristics, exposure size, 
scale and sudden water inrush water characteristics, and other factors. In view of the difficult construction, drainage and construction of tunnel safety aspects of adverse slope construction risk is far greater than the slope of the tunnel construction, tunnel in karst water inrush simulation by reverse-sloping tunnel, which FAVOR model is shown in Figure 1. Potential sudden water simulated by the cube side length of $20 \mathrm{~m}$, are connected in the middle by pipes and tunnels of RADIUS $1 \mathrm{M}$, as the water path. Calculation model has the total element 343,444, where active cell 168,210, calculating the time for $500 \mathrm{~s}$.

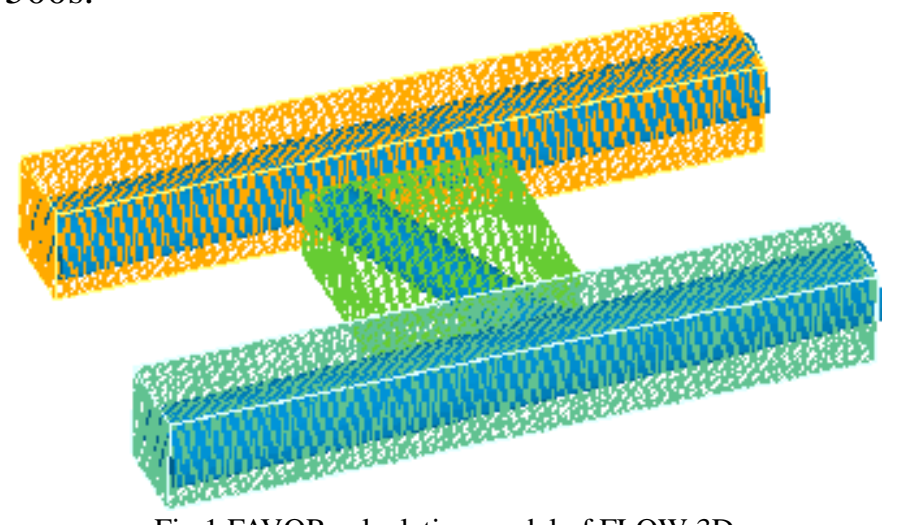

Fig.1 FAVOR calculation model of FLOW-3D

\section{The process of water inrush in Karst Tunnel}

Karst water gushing of tunnel construction in karst tunnel mouth shapes vary widely, and there are no rules to follow. Water shape differences will result in an outburst of groundwater flow difference. But for tunnel seepage, the same area with different shapes of water makes little difference if only considering water vent area. Rock Tunnel water burst shapes can be reduced to a circle, on the assumption that RADIUS respectively, $0.25 \mathrm{~m}, 1 \mathrm{~m}$, and $2 \mathrm{~m}$. On this basis, research revealed an area of effect. Inrush water size water storage size, which directly affect the duration of water inrush, water pressure and water per unit time, determine the harmfulness of water, it is necessary to study the different sizes of water inrush, or storage. Three different water scale using water inrush are respectively, $1000 \mathrm{~m}^{3}, 8000 \mathrm{~m}^{3}$ and $27000 \mathrm{~m}^{3}$ as a data point on the water inrush effects. As Bao Feng tunnel as shown in Figure 2, the water inrush contains a mixture of clay, sand and stone of gravity-driven water inrush and vary its flow and groundwater, and the key factors affecting migration is the density and viscosity. Therefore this article as a starting point, study the density and viscosity of inrush water influence the size of the study. Because movement patterns numerical simulation analysis of the karst water bursting need consider many influence factors, there are a number of different data points. If all parameters are combined and analyzed with heavy workloads, inefficient, nor necessary, to effectively analyze the results, it is difficult to simply analysis on leading factors of karst tunnel effect of water movement patterns to solve migration problems of water bursting. Following the use of single-factor method of karst water gushing in tunnel condition selection movement pattern and analysis procedures is as follows. Firstly, there is a determining reference condition. Secondly, the data points of every factors in the reference conditions for rotation change there is only one factor at a time point, so that there is one data point per rotation for a new operating mode. Gravity-driven water movement patterns in karst tunnel numerical simulation analysis of the specific condition is shown in table 1. 


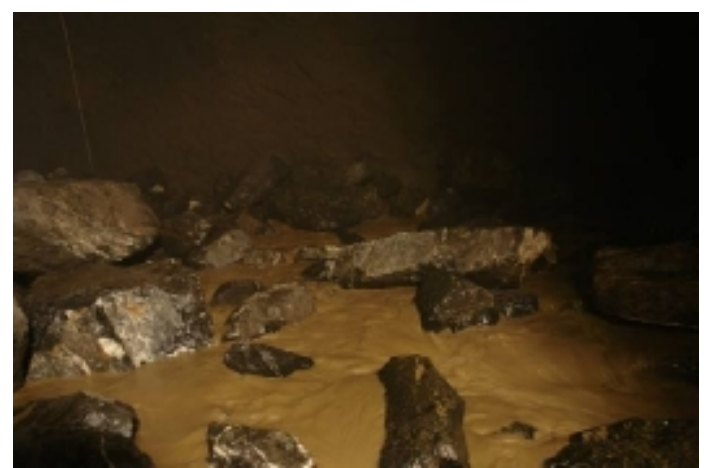

Fig.2 Water inrush in karst tunnel gushing Tab 1 Calculation mechanical parameters

\begin{tabular}{ccccc}
\hline $\begin{array}{c}\text { Working } \\
\text { conditions }\end{array}$ & Expose area radius $(\mathbf{m})$ & Water inrush size $\left(\mathbf{m}^{\mathbf{3}}\right)$ & $\begin{array}{c}\text { Water inrush viscosity } \\
(\mathbf{P a} \times \mathbf{s})\end{array}$ & $\begin{array}{c}\text { Water inrush density } \\
\left(\mathbf{k g} / \mathbf{m}^{\mathbf{3}}\right)\end{array}$ \\
\hline $\mathrm{C}$ & 1 & 8000 & $1.005 \times 10^{-3}$ & 1000 \\
\hline $\mathrm{R} 1$ & 0.25 & 8000 & $1.005 \times 10^{-3}$ & 1000 \\
\hline $\mathrm{R} 2$ & 2 & 8000 & $1.005 \times 10^{-3}$ & 1000 \\
\hline V1 & 1 & 1000 & $1.005 \times 10^{-3}$ & 1000 \\
\hline V2 & 1 & 27000 & $1.005 \times 10^{-3}$ & 1000 \\
\hline F1 & 1 & 8000 & 0.3 & 1500 \\
\hline F2 & 1 & 8000 & 3.5 & 1520 \\
\hline
\end{tabular}

Remark: $C$-reference condition, $R_{\text {Radius }}, V_{\text {Water, }} F$ Water inrush under $20^{\circ} \mathrm{C}$

\section{Results and analysis}

Because water has a lot of relevance, as shown in Figure 3-8, water inrush velocity, discharge, turbulent kinetic energy, the average kinetic energy, left line tunnel drainage rate, right line tunnel drainage rate curve at the same time, respectively.

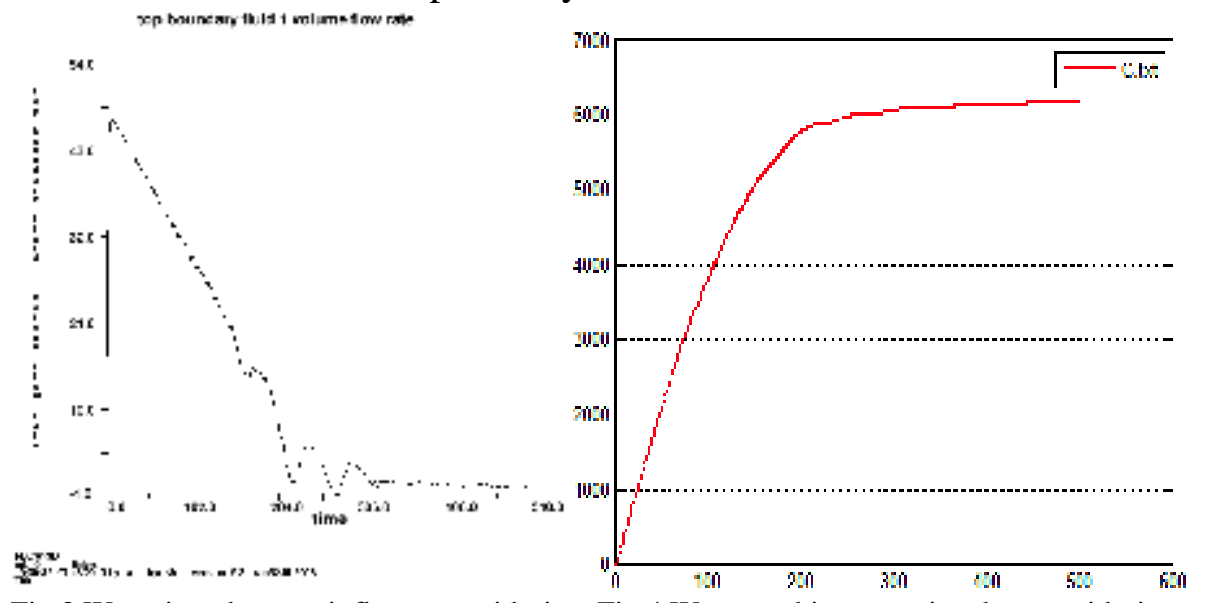

Fig.3 Water inrush water inflow rate with time Fig.4 Water gushing quantity change with time

As shown in Figure 3, water inrush water rate curves show that water inrush from production to the end of the tunnel continues a total continuous 510s. Seen from them, in the 200s water inflow rate to fluctuate in the future, water reached the $5900 \mathrm{~m}^{3}$ as shown in Figure 4. And water in the 300S end, this inflow has reached the $6000 \mathrm{~m}^{3}$ as shown in Figure 4. Obviously, there is a shorter duration of karst water bursting water in tunnel. 


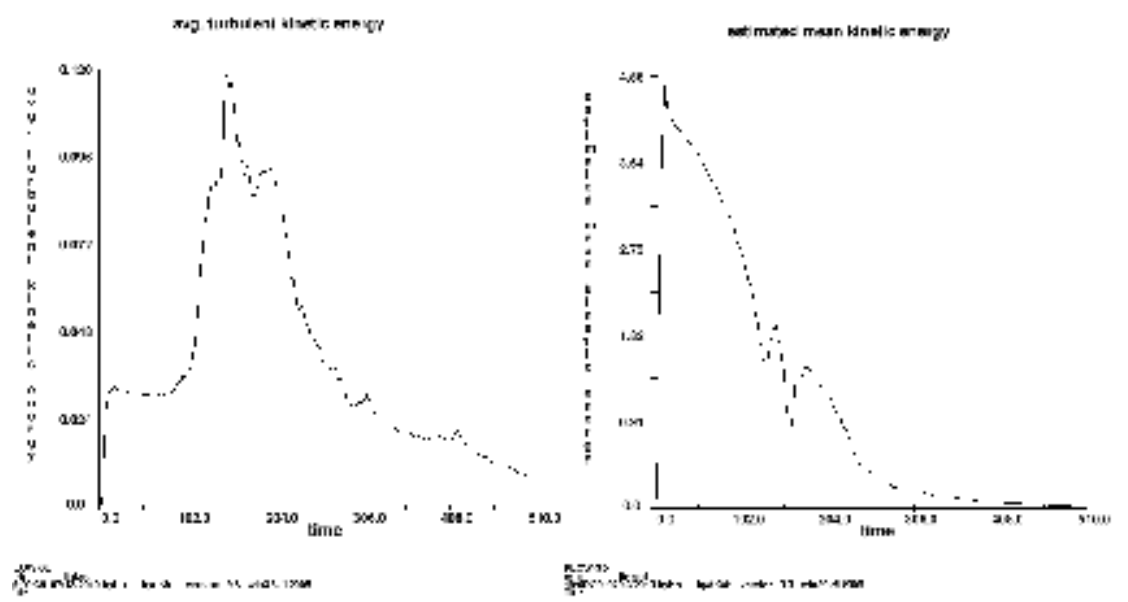

Fig.5Turbulent kinetic energy change curve with time Fig.6 The average kinetic energy variation with time

Figure 5-figure 8 shows that, before the water inrush disaster occurred in the 140s, discharged water inrush from baofeng left line tunnel for the treasure peak is slightly higher than the main tunnel cross passage to the base minimum. However, after bursting water disaster occurred 140s, basic bursting water by baofeng tunnel right line discharge, its main causes for treasure peak tunnel left line tunnel within bursting water movement speed reduced and kinetic energy reduced due to bursting water of gravity role. Bursting water occurred early led to initial stage Chung water began to tunnel excavation surface flow, thus formed turbulence, this form can from Figure 5-figure 8 in the can see. Besides, treasure peak tunnel within bursting water in tunnel within of flow state can is divided into following three a stage. Firstly, in bursting soaked before 100s, due to gravity drive force larger, bursting water shipped moved speed larger, even hole within floor for inverse Po, bursting water also didn't formed return, basic are directly from left line discharge. Secondly, 100s-140s after in bursting water disaster occurred, bursting water migration speed began reduced, bursting water return from left line tunnel mouth began produced, and gradually to excavation surface aspects movement, At Chung water still from left line discharge. Thirdly, 140s after bursting water disaster occurred around, bursting water shipped moved turbulent kinetic energy reached maximum, bursting water return has movement to cross channel near, at bursting water turbulent kinetic energy and Chung water kinetic energy basic offset, Chung water has cannot from left line Gush, and with bursting water mouth Chung water of continues to migration, left line tunnel hole within water constantly uplift, until didn't had cross channel late surface. Water began to flow through the cross-channel tunnel to the right. Due to the reverse slopes, gathered near the water first in the face and then released by the right line.
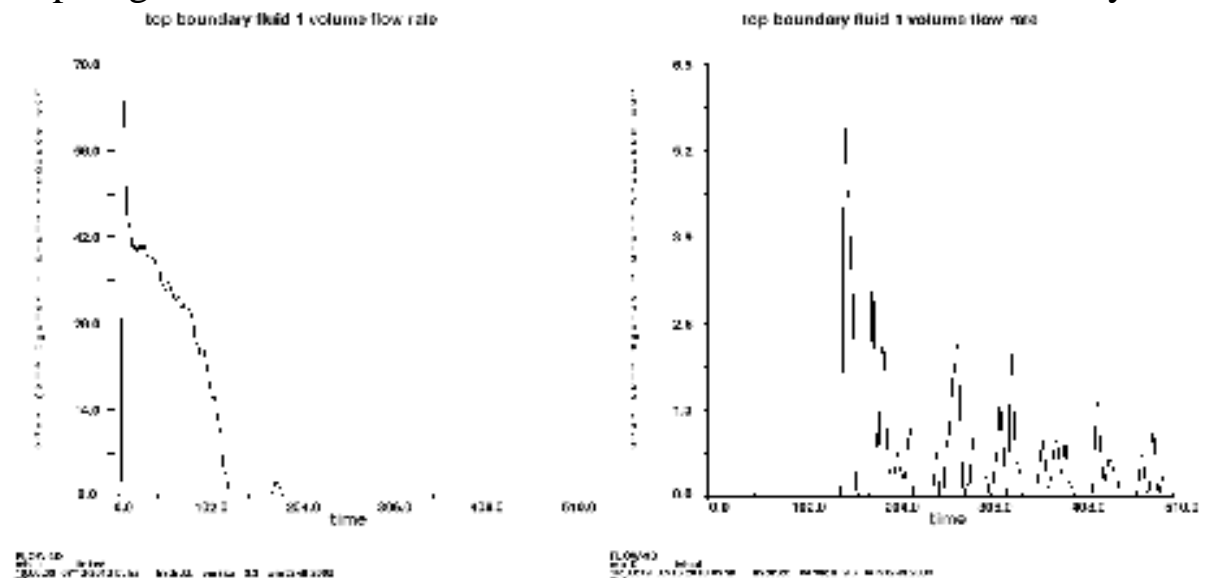

Fig.7 Left line tunnel drainage rate changes with time Fig.8 Right line tunnel drainage rate changes with time

Inrush water from the tunnel transport velocity and pressure profiles can be seen in figures 9-12, in the initial stage of gushing water, water inrush migrate faster, up to $17 \mathrm{~m} / \mathrm{s}$, and waves to the face behind the advance. But because of water gushing in tunnel cross section area restrictions, resulting in sudden inflow of water is much less than the amount of water in the tunnel the tunnel excavation surface cross section size, so sudden water inflow in the tunnel at the bottom of the water flowing, 
even in the deepest is $2 \mathrm{~m}$ the only deep inside the cave, but would cause great harm to people's lives. This shows that the layout of ladders and other equipment in the tunnel can effectively ensure the safety of construction personnel unable to flee in time. According to Baofeng simulation of tunnel water burst after burst water movement inside the tunnel, can effectively optimize tunnel escape routes. Due to the occurrence of karst water gushing in tunnel transient, requires builders to be able to choose the right at that moment how to survive can often escape or evade until reinforcements, otherwise there will be life-threatening. As shown in Figure 9-12 water inrush from this scale, if construction workers near the cross passage, you can escape to another tunnel right line, you will need to choose the nearest ladder and other equipment, hidden high in the tunnel waiting to be rescued.
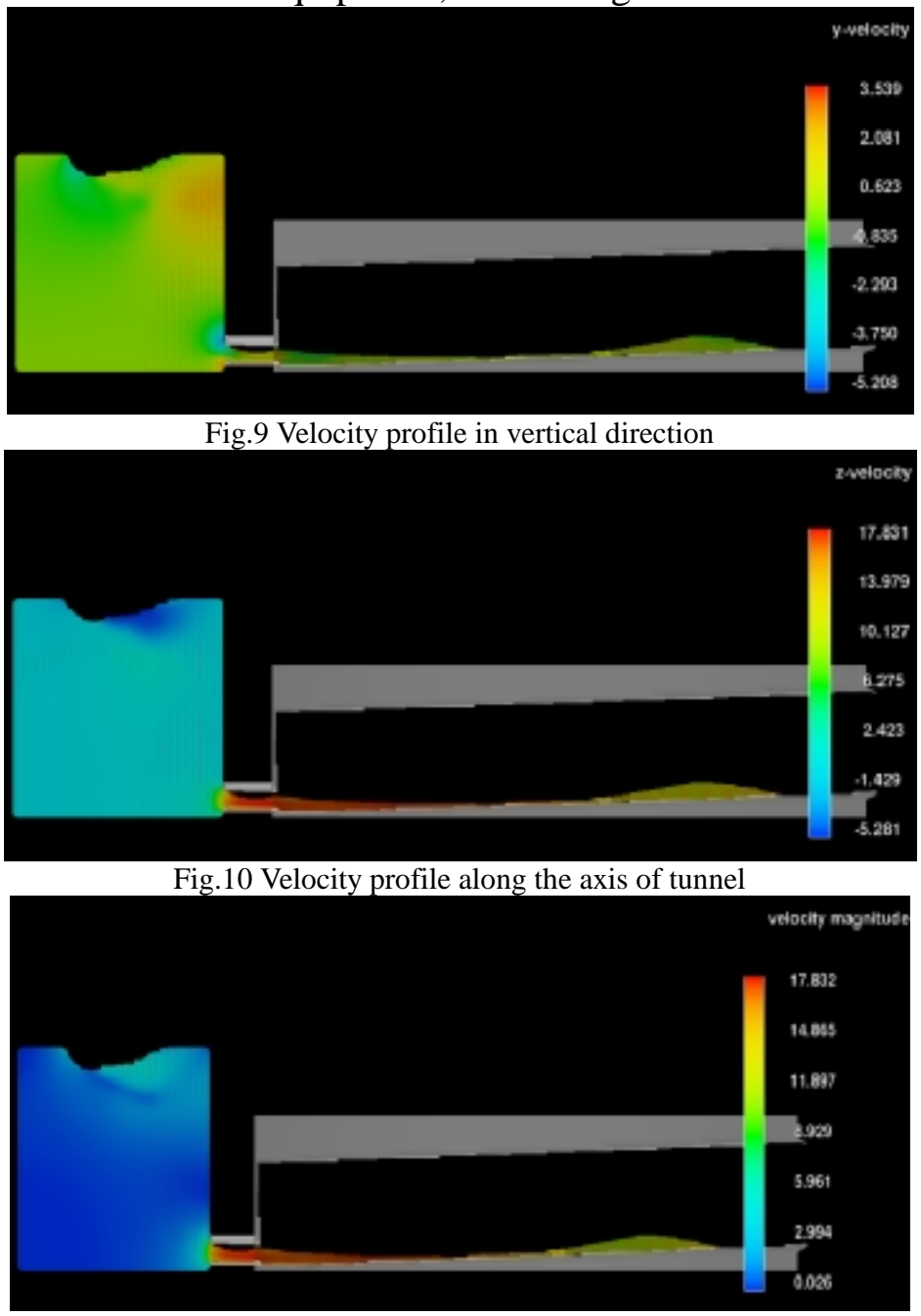

Fig.11 The total water inflow velocity profile

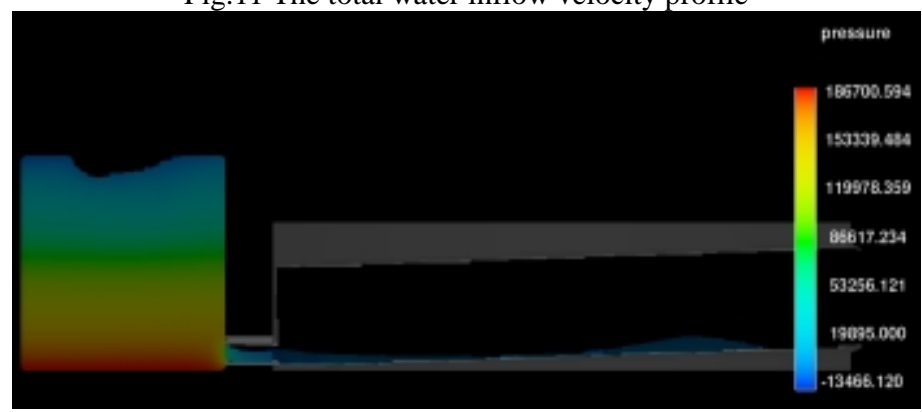

Fig.12 The total water inflow pressure profile

As shown in Figure 9-12 to water quantity, water pressure and water inrush of water parameters, by means of simulation of karst water bursting in tunnel movement, you can estimate the size and scale of tunnel in karst water inrush, theoretical basis for works on water inrush disaster occurred. In the process of tunnel water burst treatment, to focus on the grout removal process, methods, parameters, and other content, also focuses on water inrush and water conditions. C reference conditions, as long 
as the cross section of water gushing in this scale as long as the water are much smaller than the cross section of the tunnel, when flowing water bursting in tunnel for free flow, analysis of water pressure can be briefly addressed. Because of karst water bursting in tunnel calculation model of movement patterns of the same and, therefore, flow of water gushing in tunnel routes are also consistent analysis on turbulent kinetic energy, and the average kinetic energy, and so on can also be briefly addressed. Discharge over time and the potential magnitude of water inrush, water area as well as directly related to the nature of the fluid. For other operating conditions, this analysis will focus on the yield curve over time. For each condition is completed, use Matlab after the corresponding handler, extraction of water per unit time and time waiting for data, draws a similar condition of discharge per unit time and time curves, Figure 13 for variable water bursting area radius of water inflow rate curve over time.

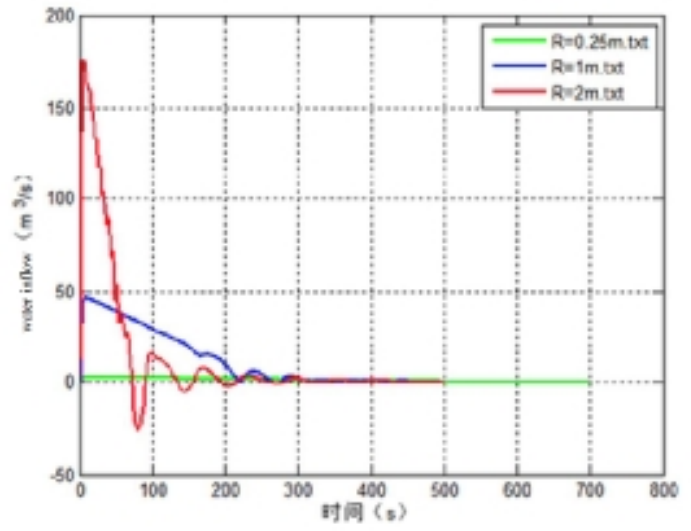

Fig.13 Change curve radius of water inflow rate and the time of water inrush

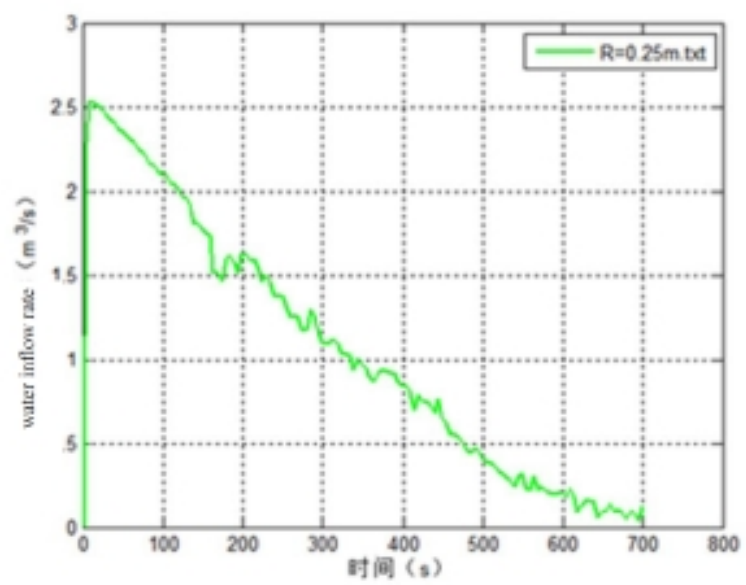

Fig. 14 Water inflow rate curve under $\mathrm{R}=0.25$

According to table 1 of the morphological condition of karst water bursting in tunnel movement, as can be seen in Figure 14 shows the water gushing in tunnel water burst rate is an area of major impact. In bursting water total, and bursting water pressure and bursting water time, bursting water parameter consistent premise Xia, assumes that bursting water mouth RADIUS for $0.25 \mathrm{~m}$ Shi, maximum Chung water rate in $3.5 \mathrm{~m} 3 / \mathrm{s}$, Chung water time continued more than 700 seconds; assumes that bursting water mouth RADIUS for $1 \mathrm{M}$ Shi, maximum Chung water rate surge to $48 \mathrm{~m}^{3} / \mathrm{s}$, Chung water continued more than 300 overs; but Dang assumes that bursting water mouth RADIUS for $2 \mathrm{~m}$ Shi, maximum Chung water rate reached $175 \mathrm{~m}^{3} / \mathrm{s}$, Chung water continued 100s around. So Karst tunnel excavation process, when faced with a potential water inrush in addition to ongoing physical detection outside, is sure to perform the drilling of the existing principles in order to avoid large area exposed in karst areas. 


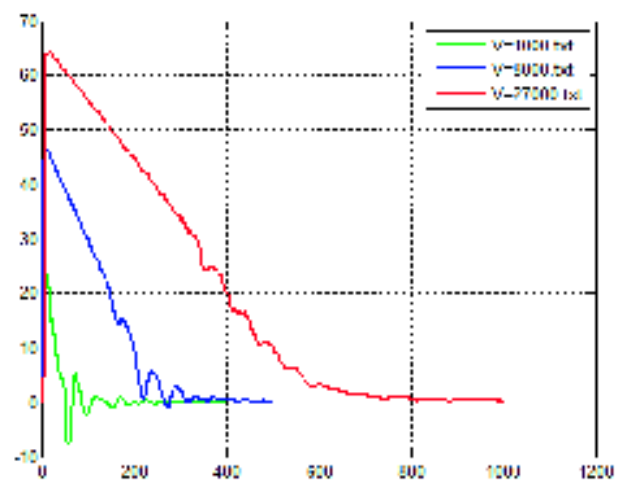

Fig. 15 Variable flow rate and time curve of sudden water scale

Figure 15 shows that the karst water bursting in tunnel of water inrush rate impact of a larger scale. When $103 \mathrm{~m} 3$ is tunnel in karst water inrush, water burst rates of up to $28 \mathrm{~m}^{3} / \mathrm{s}$ and when $203 \mathrm{~m}^{3}$ is tunnel in karst water inrush, water burst rates of up to $47 \mathrm{~m}^{3} / \mathrm{s}$, water burst duration is $300 \mathrm{~s}$; when $303 \mathrm{~m}^{3}$ is tunnel in karst water inrush, water burst rates of up to $64 \mathrm{~m}^{3} / \mathrm{s}$, water burst duration is of $600 \mathrm{~s}$. Karst tunnel excavation when facing water inrush, water inrush scale cannot be selected, but on the basis of geological prediction results, advance to grasp scale magnitude so as to effectively prevent water inrush disaster preparedness-related equipment and materials technology of Grouting and blocking water equipment.

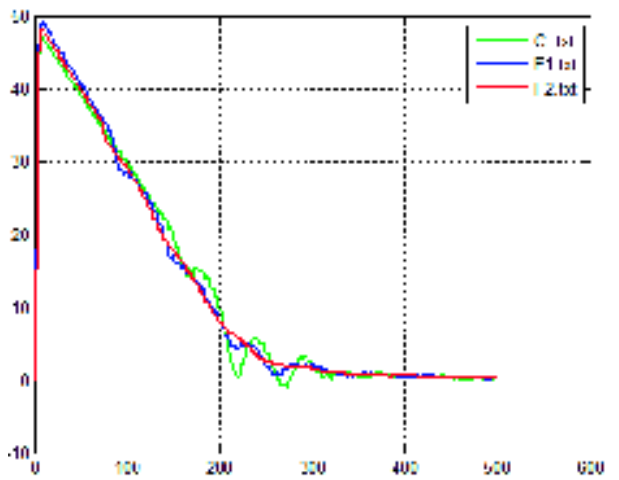

Fig.16 Water inflow rate curve of groundwater characteristics change with time

Viscosity and density of water inrush of water bursting rate influences can be seen from Figure 16. Maximum rate is inversely proportional to the viscosity of water inrush, is proportional to the density. This is mainly due to the increase in density will make the water pressure increases, which results in increase of water inrush in the driving force, while the viscosity of water inrush in the kinetic energy of water consumed in the process and rate fluctuations affected by the excavation of karst groundwater, and viscosity of the fluid decay at a rate of two relatively smooth, as stated above can be further confirmation of believable.

\section{Conclusions}

Based on the treasured peak tunnel, the potential bursting water geological body is nearby the dissolved cavity fill real and the rock dissolved groundwater. It is bursting water process in the small water pressure. The main cause is in itself gravity role Xia of gravity gradient drive flow of status. The research has rock dissolved tunnel in gravity gradient drive shed of bursting water movement form. From the aforementioned results and analyses, it can be found several significant conclusions for numerical simulation analysis of karst tunnel water bursting movement.

(1) Bursting water of Karst tunnel from occurred to ended continued 510S. Among them, the water inflow rate to fluctuate after the 200 s, inflow to reach $5900 \mathrm{~m} 3$. But this inflow water in the $300 \mathrm{~S}$ has reached $6000 \mathrm{~m} 3$. Obviously, this inflow has the shorter duration of karst water bursting.

(2) The burst water in karst tunnel is within the first 140s from the left line tunnel. The main reason of the sudden water discharge for the underside of the cross-channel tunnel is slightly above the minimum. 140s later, drainage is mainly from the right line out. And for the left line tunnel, the burst 
water slows and kinetic energy is reduced due to gravity. The causes above lead to the burst water begin to flow from the tunnel face and create turbulence.

(3) The karst water inflow into tunnel in the start-up phase, bursting water migration is fast, up to $17 \mathrm{M} / \mathrm{s}$, and filled water inrush in the wave forward. Limited by the nozzle cross sectional area bursting into relative to the amount of water in the tunnel, the tunnel cross section size is smaller, the sudden flow of water inflow in the tunnel at the bottom of the water body.

(4) The viscosity and density of water inrush has little effect on the water inrush rate. The water inrush rate is inversely proportional to the viscosity and is proportional to the density and results in increase of water driving force of gravity. This is because the sudden increase in water density will make the water pressure increases and the viscosity. The viscosity consumed on the kinetic energy of water in the process.

\section{References}

[1] MENG Yan, LEI Ming-tang. The advance and suggestion for the study on discharge rate in karst tunnel gushing[J].Carsologica Sinica, 2003, 22 (4) : 287-292.

[2] ZHOU Zong-qing, LI Shu-cai, LI Li-ping et al. Attribute recognition model of fatalness assessment of water inrush in karst tunnels and its application[J].Rock and Soil Mechanics, 2013, 34 (3) : 818-829.

[3] WANG Jian-xiu, YANG Zhong-li, HE Jing. The procedure proposed to prevent Karstgroundwater's blow (bursting) in large scale underground engineering[J]. Hydrogeology engineering geology, 2001, 4:49-52.

[4] XIE Dong-sheng, SHI Shao-shuai, CHEN Shi-lin, et al.The precursor law of inrush of clay and water in a high-risk karst tunnel and its application[J].Journal of Shandong University (Engineering Science) , 2012, 42 (1) :81-98.

[5] XIE Xian-guang.Typical tunnel of Dazhiping water and mud inrush event analysis and its enlightenment [J].China Highway, 2009.15:94-95.

[6] HUANG Xiong-Jun. Influence Factors of Water Bursting and Mud Bursting of Karst Tunnels and Its Countermeasures[J].Journal of Railway Engineering Society, 2013, 172 (1) :45-53. 